\title{
Anthranilic acid from Ralstonia solanacearum plays dual roles in intraspecies signalling and inter-kingdom communication
}

\author{
Shihao Song ${ }^{1,2} \cdot$ Wenfang Yin ${ }^{1} \cdot$ Xiuyun Sun ${ }^{1,2} \cdot$ Binbin Cui ${ }^{2} \cdot$ Lei Huang $^{2} \cdot$ Peng $\mathrm{Li}^{3} \cdot$ Liang Yang $^{4} \cdot$ Jianuan Zhou $^{1} \cdot$ \\ Yinyue Deng $\mathbb{( 1 0}^{2}$
}

Received: 11 December 2019 / Revised: 2 May 2020 / Accepted: 7 May 2020 / Published online: 26 May 2020

(c) The Author(s) 2020. This article is published with open access

\begin{abstract}
Quorum sensing (QS) signals are widely utilized by bacteria to regulate biological functions in response to cell population density. Previous studies have demonstrated that Ralstonia solanacearum employs two different types of QS systems. We report here that anthranilic acid controls important biological functions and the production of QS signals in R. solanacearum. It was demonstrated that the biosynthesis of anthranilic acid is mainly performed by TrpEG. The accumulation of anthranilic acid and the transcription of $\operatorname{trpEG}$ occur in a cell density-dependent manner in $R$. solanacearum. Both the anthranilic acid and TrpEG homologues are conserved in various bacterial species. Moreover, we show that Sporisorium scitamineum sexual mating and hypha formation are strongly inhibited by the addition of exogenous anthranilic acid. Our results suggest that anthranilic acid is important for the physiology of bacteria in addition to its role in inter-kingdom communication.
\end{abstract}

\section{Introduction}

Quorum sensing (QS) is a cell-to-cell communication mechanism used by many bacterial species to coordinate communal behaviour in response to cell density to regulate phenomena such as virulence, biofilm formation, motility and antibiotic production [1-3]. When a minimal threshold concentration of a QS signal is reached, it will cause transcriptional activation and repression of a large regulon of

These authors contributed equally: Shihao Song, Wenfang Yin

Supplementary information The online version of this article (https:// doi.org/10.1038/s41396-020-0682-7) contains supplementary material, which is available to authorized users.

$\triangle$ Yinyue Deng

dengyle@mail.sysu.edu.cn

1 College of Agriculture, South China Agricultural University, Guangzhou 510642, China

2 School of Pharmaceutical Sciences (Shenzhen), Sun Yat-sen University, Guangzhou 510275, China

3 Ministry of Education Key Laboratory for Ecology of Tropical Islands, College of Life Sciences, Hainan Normal University, Haikou 571158, China

4 School of Medicine, Southern University of Science and Technology, Shenzhen 518055, China target genes. The first well-characterized QS system utilized by many Gram-negative bacteria is mediated by N-acyl-Lhomoserine lactones (AHLs) as extracellular signalling molecules [2, 4-6]. In addition to AHL family signals, there are many other kinds of QS signals, such as diffusible signal factor (DSF)-type signals [3, 7], autoinducer 2 [8, 9], methyl 3-hydroxypalmitate (3-OH PAME) [10], 2-heptyl-3hydroxy-4(1 H)-quinolone (PQS) [11], 2-heptyl-4quinolone (HHQ) [12], AI-3 [13], bradyoxetin [14], and diketopiperazines [15].

Ralstonia solanacearum is a soil-borne bacterium that causes a lethal disease known as "bacterial wilt" in more than 200 plant species worldwide [16-18]. Previous studies showed that methyl 3-OH PAME is a QS signal that plays a major role in the global regulation of $R$. solanacearum virulence factors, including extracellular polysaccharide (EPS), cell wall-degrading enzymes and motility $[10,16,19]$. It was later found that methyl 3hydroxymyristate (3-OH MAME) was synthesized by several $R$. solanacearum strains [19]. 3-OH PAME or 3-OH MAME is synthesized by $\mathrm{PhcB}$, which is a methyltransferase. When the QS signals reach a threshold level, it activates the histidine kinase $\mathrm{PhcS}$ to phosphorylate the response regulator PhcR and increase the expression levels of PhcA, which is a LysR-type transcriptional regulator that plays a central role in the $p h c$ system as a global regulator $[10,20,21]$. In addition, it was found that $R$. solanacearum 
possesses a solIR QS system, which is a luxI/luxR homologue that is upregulated by the phc system $[10,19,22]$. The abolition of solIR eliminates the synthesis of AHL signals but does not affect virulence factor production in $R$. solanacearum AW1 strain [22].

Microbial crosstalk between bacteria and fungi commonly exists in many ecological settings. Small molecule signals are increasingly recognized as important interspecies or inter-kingdom communication signals in microbial communities [23]. Ralsolamycin from $R$. solanacearum has been identified as an inducer of chlamydospore formation in fungi such as Ascomycetes, Basidiomycetes and Zygomycetes [24]. The biosynthesis of ralsolamycin in $R$. solanacearum is modulated by the two nonribosomal peptide synthetases, RmyA and RmyB [25]. Interestingly, our previous study revealed that the expression of $r m y A B$ was controlled by the phcBSR QS system [26], suggesting that QS plays an important role in inter-kingdom communication between $R$. solanacearum and fungi. In this study, we showed that anthranilic acid produced by TrpEG in $R$. solanacearum inhibits sexual mating and hypha formation in Sporisorium scitamineum. The inactivation of the anthranilate synthase gene, $\operatorname{trp} E G$, disrupts biofilm formation, motility activity, virulence factor production and pathogenicity in $R$. solanacearum. The addition of exogenous anthranilic acid restored these phenotypes of the trpEG deletion mutant strain. Furthermore, it was indicated that anthranilic acid controls the expression levels of many genes in $R$. solanacearum. As $R$. solanacearum and $S$. scitamineum are frequently encountered plant pathogens, our data suggest that in addition to the important role of anthranilic acid in the physiology of $R$. solanacearum, it also engages in an antagonistic interaction whose importance to microbial ecology and pathogenesis is now becoming evident.

\section{Materials and methods}

\section{Bacterial strains and growth conditions}

The bacterial strains and plasmids used in this work are listed in Supplementary Table $1 . R$. solanacearum GMI1000 (ATCCBAA-1114) was obtained from the American Type Culture Collection and maintained at $28^{\circ} \mathrm{C}$ in 2,3,5-triphenyltetrazolium chloride medium (TTC medium) containing $1 \%$ tryptone, $0.1 \%$ casamino acids, $0.5 \%$ glucose, and $0.005 \%$ 2,3,5-triphenyltetrazolium chloride [27]. Luria-Bertani medium ( 11 contains $10 \mathrm{~g}$ tryptone, $5 \mathrm{~g}$ yeast extract and $10 \mathrm{~g} \mathrm{NaCl}, \mathrm{pH} 7.0$ ) was used to maintain Escherichia coli. S. scitamineum was cultured in YePS agar medium (10 g yeast extract, $20 \mathrm{~g}$ peptone, $20 \mathrm{~g}$ sugar, $20 \mathrm{~g}$ agar per litre) [28]. The following antibiotics were added when necessary: ampicillin and kanamycin at $100 \mu \mathrm{g} \mathrm{ml}^{-1}$; tetracycline, $10 \mu \mathrm{g} \mathrm{ml}^{-1}$; and gentamicin, $10 \mu \mathrm{g} \mathrm{ml}^{-1}$. Bacterial growth was determined by measuring the optical density at a wavelength of $600 \mathrm{~nm}$.

\section{Purification and structural analysis of anthranilic acid from $R$. solanacearum}

R. solanacearum GMI1000 cells were cultured in TTC medium for $48 \mathrm{~h}$, and the supernatant was extracted with an equal volume of ethyl acetate. Following evaporation of the ethyl acetate, the residue was dissolved in methanol and subjected to HPLC analysis in a C18 reverse-phase column (XBridge, $10 \mu \mathrm{m}, 19 \mathrm{~mm} \times 250 \mathrm{~mm}$, Waters) and eluted with methanol-water (from 35:65 to 100:0 v/v) at a flow rate of $7 \mathrm{ml} / \mathrm{min}$. The active fractions were detected, concentrated, purified by HPLC using a semi-preparative C18 reverse-phase column (Gemini-NX, $5 \mu \mathrm{m}, 10.0 \mathrm{~mm} \times 250$ $\mathrm{mm}$, Phenomenex) and eluted with methanol-water (from $35: 65$ to $100: 0 \mathrm{v} / \mathrm{v}$ ) at a flow rate of $3 \mathrm{ml} / \mathrm{min}$. Peaks were monitored using a ultraviolet (UV) detector at $210 \mathrm{~nm}$ and were collected and assayed. The experiment was performed according to the previous method [27].

The ${ }^{1} \mathrm{H},{ }^{13} \mathrm{C}$, and DEPT135 nuclear magnetic resonance (NMR) spectra in $\mathrm{CD}_{3} \mathrm{OD}$ solution were obtained using a Bruker AV-500 (Bruker Instrument, Inc., Zurich, Switzerland) spectrometer operating at $500 \mathrm{MHz}$ for ${ }^{1} \mathrm{H}$ or 125 $\mathrm{MHz}$ for ${ }^{13} \mathrm{C}$. High-resolution electrospray ionization mass spectrometry (HR-ESI-MS) was performed on a Waters QTof Premier high-resolution mass spectrometer (Waters, Milford- MA, USA) [27].

\section{Analysis of sexual mating and filamentation in $S$. scitamineum}

The haploid S. scitamineum MAT-1 and MAT-2 cell lines expressing green fluorescent protein (GFP) and red fluorescent protein (RFP), respectively, were used for the bioassays of the sexual mating and filamentation of $S$. scitamineum. YePS plates were cut into separated slices $(0.6 \times$ $6 \mathrm{~cm})$. Ten microlitres of anthranilic acid or other chemicals were spotted at the end of the slices in the agar plate at 0 , $10,25,50$ or $100 \mu \mathrm{M}$. Thereafter, the MAT- 1 and MAT-2 cell line mixture $\left(1 \mu \mathrm{l}, \mathrm{OD}_{600} \approx 1.5\right)$ was spotted on the slices. The plates were incubated at $28^{\circ} \mathrm{C}$ for $48 \mathrm{~h}$ until white hyphae grew in the negative control. For microscopic analyses, S. scitamineum cells were cultured in YePS liquid medium for $24 \mathrm{~h}$. The cells were then transferred to YePS plates with or without the addition of anthranilic acid for 24 $\mathrm{h}$, then washed off with sterile water and observed and imaged using a Leica DMi8 microscope equipped with a Leica DFC450 C camera (Leica, Wetzlar, Germany). Standard filter sets of GFP, RFP and differential 
interference contrast were used [29]. The bioassay was repeated at least three times.

\section{Construction of reporter strains and measurement of $\beta$-galactosidase activity}

The trpEG promoter was amplified using the ptrpEG-F and ptrpEG-R primer pair listed in Supplementary Table 2 and then purified prior to ligation with the expression vector pME2-lacZ, which was digested with the same enzymes. The $\operatorname{trpEG}$ reporter was introduced into the $R$. solanacearum GMI1000 and trpEG mutant strains by electroporation. Transconjugants were then selected on TTC agar plates supplemented with tetracycline and X-gal. $\beta$ galactosidase activities were assayed following the methods described previously [30]. Bacteria were cultured at 28 ${ }^{\circ} \mathrm{C}$, and the cells were harvested to measure $\beta$-galactosidase activities.

\section{Construction of in-frame deletion mutants and complementation}

$R$. solanacearum GMI1000 was used as the parental strain for the generation of in-frame deletion mutants following the methods described previously [31]. The primers used to generate the upstream and downstream regions flanking $\operatorname{trpEG}$ are listed in Supplementary Table 2. For complementation analysis, the coding regions of $\operatorname{trpEG}$ were amplified and cloned into the pLAFR3 plasmid. The resulting constructs were introduced into $R$. solanacearum GMI1000 deletion mutants using electroporation.

\section{Virulence assays in tomato plants}

The analysis of the virulence of the $R$. solanacearum WT, $\Delta$ trpEG and complementation strains was performed in an AIRKINS greenhouse $\left(28{ }^{\circ} \mathrm{C}\right.$, light $16 \mathrm{~h}$ and dark $\left.8 \mathrm{~h}\right)$. A mixture including field soil, sand, and compost (1.25:1.25:0.5) was prepared and autoclaved at $121{ }^{\circ} \mathrm{C}$ for $20 \mathrm{~min}$. Tomato seeds (Jinfeng 1) were surface-sterilized in $2 \% \mathrm{NaClO}$ for $3 \mathrm{~min}$ and $75 \%$ ethanol for $2 \mathrm{~min}$, rinsed 3 times in sterile water, and then planted in soil. $R$. solanacearum cells were grown in TTC medium to an $\mathrm{OD}_{600}=$ 1.0. Aliquots of $5 \mathrm{ml}$ of the $R$. solanacearum $\mathrm{WT}, \Delta \mathrm{trpEG}$,

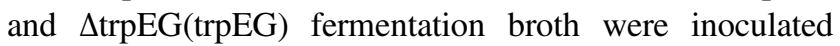
onto the tomato seedlings. Each treatment included 25 replicates [27].

\section{Analysis of $\boldsymbol{R}$. solanacearum cell numbers in plants}

One gram samples of plant roots and stems were collected and milled in $9 \mathrm{ml}$ of sterilized water for $20 \mathrm{~min}$. The suspensions were serially diluted and spread on TTC plates.
The plates were incubated at $28^{\circ} \mathrm{C}$ for $48 \mathrm{~h}$. Then, the numbers of $R$. solanacearum cells were counted [27].

\section{Statistical analysis}

Statistical analyses were performed with Prism8 software (GraphPad). The data are presented as the means \pm standard deviations of three independent experiments. Statistical significance was indicated as follows: $* p<0.05 ;{ }^{* *} p<0.01$; $* * * p<0.001$ (unpaired $t$ test). All results were calculated from the means of at least three replicates.

\section{Results}

\section{R. solanacearum inhibits the sexual mating and morphological transition of S. scitamineum}

A previous study showed that $R$. solanacearum produces ralsolamycin to induce chlamydospore formation in fungi [24]. As both $R$. solanacearum and S. scitamineum are plant pathogens, we investigated whether competition exists between the two pathogens. When they were grown together in the plate containing YePS medium, we found that $R$. solanacearum GMI1000 exhibited obvious inhibitory activity toward sexual mating and hypha formation in $S$. scitamineum, while $S$. scitamineum produced hyphae well when it was inoculated either alone or with E. coli DH5 $\alpha$ (Fig. 1a-c). We then extracted small molecular weight compounds from the liquid culture of $R$. solanacearum using ethyl acetate and found that the ethyl acetate extract exerted a similar inhibitory effect on sexual mating and hypha formation in S. scitamineum (Fig. 1d), suggesting that $R$. solanacearum produces some compounds with inhibitory activity against $S$. scitamineum sexual mating and morphological transition.

\section{The active component of $R$. solanacearum is anthranilic acid}

To identify the active component of $R$. solanacearum that inhibits the sexual mating and morphological transition of $S$. scitamineum, we isolated and purified the active fractions from $100 \mathrm{~L} R$. solanacearum GMI1000 culture supernatants using High Performance Liquid Chromatography (HPLC). Approximately $93.4 \mathrm{mg}$ of the purified compound showing activity that inhibits the sexual mating of S. scitamineum was obtained. HR-ESI-MS spectrometry analysis of the active compound revealed a molecular ion $[\mathrm{M}-\mathrm{H}]^{-}$with an $\mathrm{m} / \mathrm{z}$ ratio of 136.0405 , matching with a molecular formula of $\mathrm{C}_{7} \mathrm{H}_{7} \mathrm{NO}_{2}$. It was observed that there were four protons in the aromatic region in the ${ }^{1} \mathrm{H}$ spectrum, in addition to acidic protons deuterated by the $\mathrm{D} 4-\mathrm{MeOH}$ solvent. While carbons 
Fig. 1 Effect of $\boldsymbol{R}$. solanacearum on $S$. scitamineum sexual mating and morphological transition. The hypha formation of $S$. scitamineum was analysed when it was grown in a plate in the absence (a) or presence of $R$. solanacearum colonies (b), $E$. coli colonies (c) and the ethyl acetate extract of $R$ solanacearum $(\mathbf{d})$.
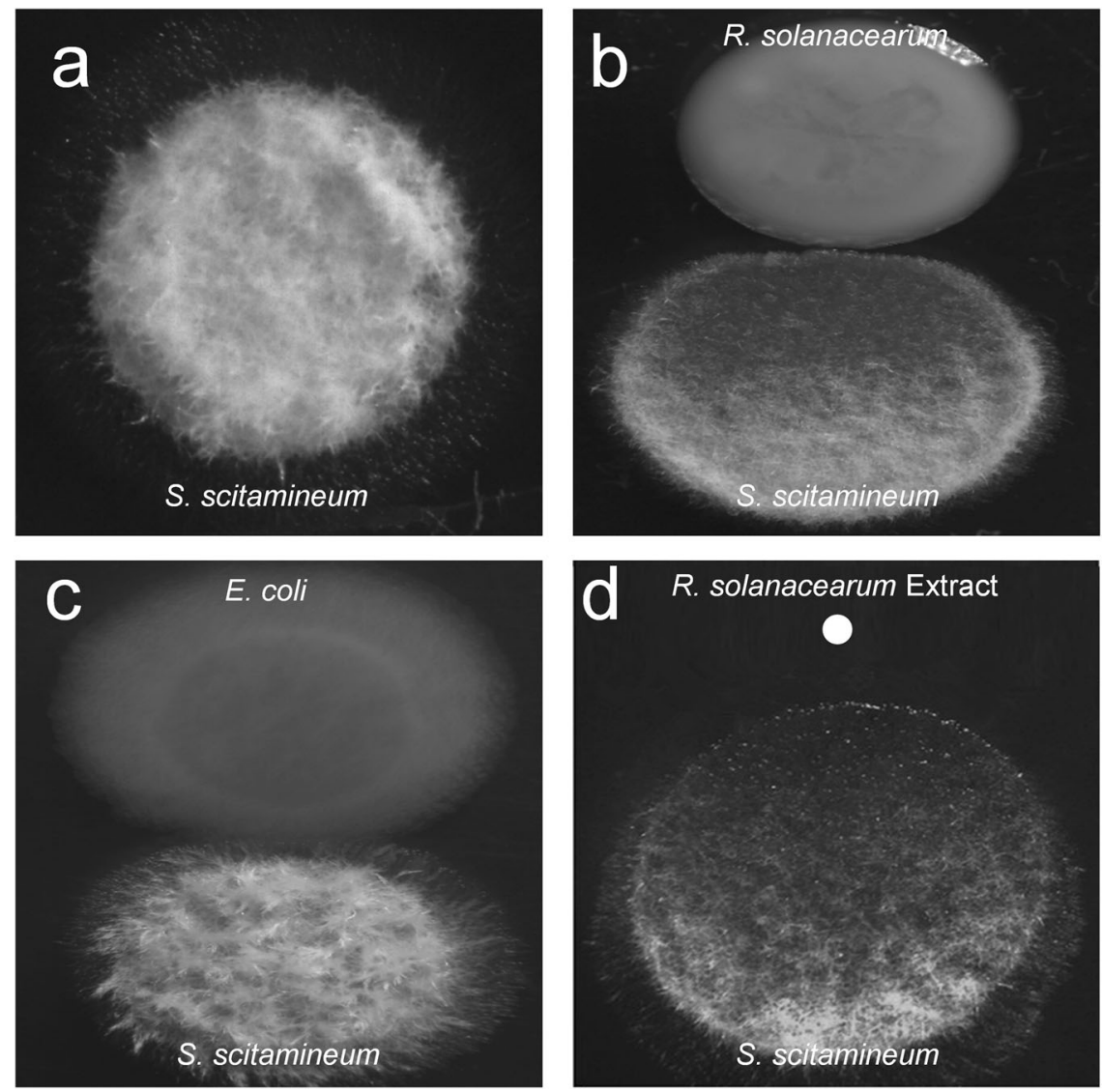

from seven distinctive chemical environments were identified from the ${ }^{13} \mathrm{C}$ spectrum, a comparison with Distortionless Enhancement by Polarization Transfer (DEPT) 135 showed the likely existence of one carbonyl $\mathrm{C}$ along with two extra $\mathrm{Cs}$ and four $\mathrm{CHs}$ in the aromatic region. The results were in agreement with the literature [32] (Supplementary Table 3), which indicated that the active compound was anthranilic acid (Fig. 2, Supplementary Fig. 1).

\section{Anthranilic acid inhibits $S$. scitamineum sexual mating and morphological transition in a dose- dependent manner}

To determine whether the effects of anthranilic acid on $S$. scitamineum are specific and related to the dose, different concentrations of the standard anthranilic acid compound were assessed for their inhibitory activity against the sexual mating and morphological transition of $S$. scitamineum (Fig. 3). These effects were assayed using a mixture of haploid S. scitamineum cell lines. In its nonpathogenic form, this fungus grows as a budding saprophytic haploid. The fusion of compatible haploids to form an infectious dikaryon initiates the pathogenic cycle. Sexually compatible haploids fuse to form the filamentous dikaryon, and the dikaryon invades plants and grows within and between plant cells, triggering the formation of characteristic tumours [33-35]. It was shown that anthranilic acid had an obvious inhibitory effect on the sexual mating of S. scitamineum at a final concentration of $10 \mu \mathrm{M}$ (Fig. 3a), and the observed inhibition increased with the addition of higher concentrations of anthranilic acid (Fig. 3a). We also used the haploid S. scitamineum MAT-1 and MAT-2 cell lines, which express GFP and RFP, respectively, for the analysis of sexual mating and hypha formation. We found that sexual mating and hyphal formation were almost completely inhibited when anthranilic acid was supplemented at a final concentration of $100 \mu \mathrm{M}$, while anthranilic acid did not affect the growth rate of $S$. scitamineum cells at this concentration (Fig. 3b, Supplementary Fig. 2). We also tested the effects of benzoic acid and one isomer of anthranilic acid, P-aminobenzoic acid, on the sexual mating and hypha formation of $S$. scitamineum and found that they exhibited no inhibitory activity (Supplementary Fig. 3).

\section{Anthranilic acid inhibits $S$. scitamineum sexual mating and filamentation by interfering with the PKA-cAMP pathway}

To explore a working model of the effect of anthranilic acid on the sexual mating and filamentation of 
Fig. 2 Structural

characterization of anthranilic acid. a ESI-MS spectra of anthranilic acid. b ${ }^{1} \mathrm{H}$ NMR spectra of anthranilic acid. ${ }^{13} \mathrm{C}$ NMR spectra of anthranilic acid. d Chemical structure of anthranilic acid.

Fig. 3 Effect of anthranilic acid on $S$. scitamineum sexual mating and morphological transition. The sexual mating and morphological transition of $S$. scitamineum were analysed when it was grown in a plate (a) and then observed in water under a fluorescence microscope (b). c Comparison of the relative fold-changes of regulatorencoding genes in $S$. scitamineum with and without the addition of anthranilic acid. d Schematic diagram of the signalling pathways that govern sexual mating and filamentation in S. scitamineum affected by anthranilic acid. a

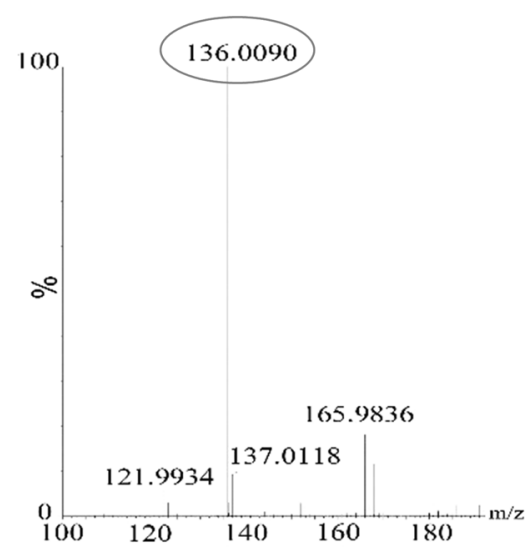

C

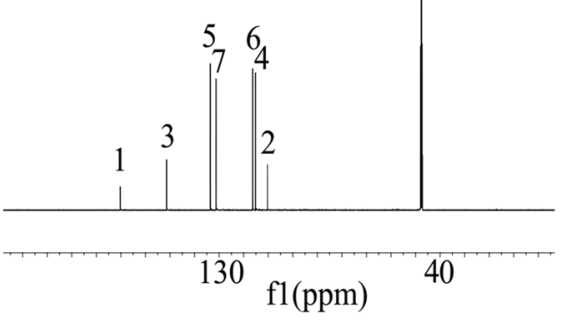

a

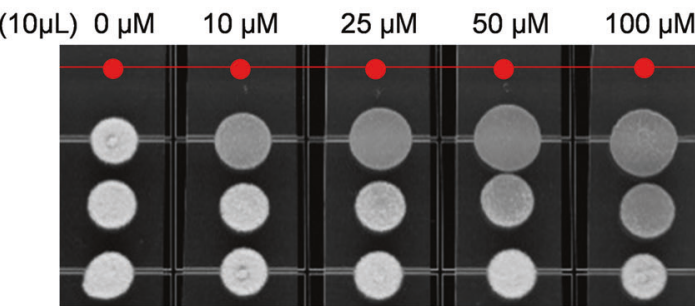

b

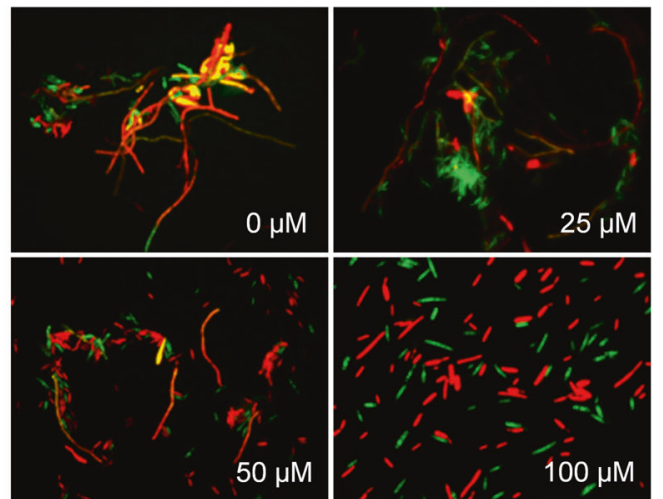

b

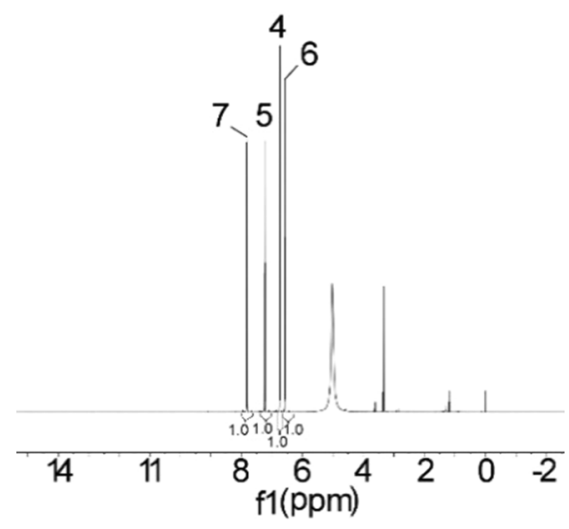

d

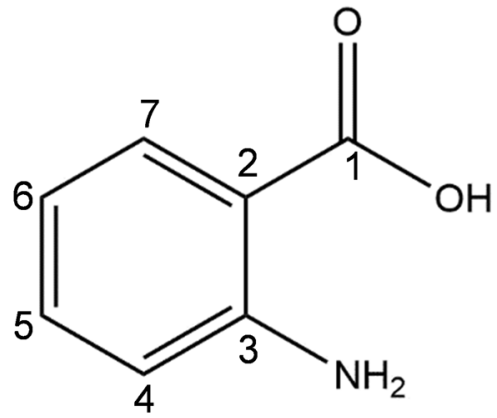

C

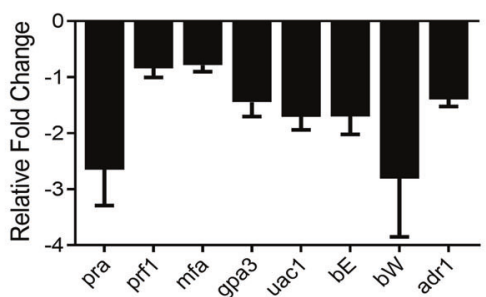

d

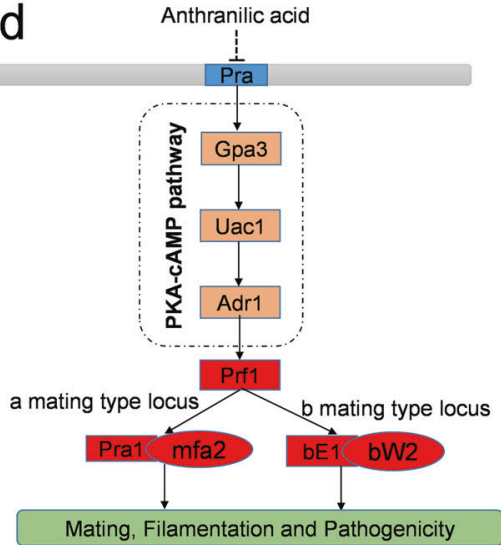


S. scitamineum, we continued to test whether anthranilic acid interfered with the signalling pathways involved sexual mating and hyphal development. In S. scitamineum, cell fusion is controlled by a pheromone/receptor system encoded by the "a" locus, while the establishment of hyphae is dependent on an active heterodimer of the homeodomain transcription factors expressed from the multiallelic "b" locus. After cell fusion, the merging of the cytoplasm of compatible cells leads to the formation of the $\mathrm{bE} / \mathrm{bW}$ transcription factor to trigger hypha formation on the surface of the plant epidermis [36]. The mitogen-activated protein kinase and cyclic AMP and protein kinase A system pathways are necessary for sensing pheromone and environmental signals. The two pathways are involved in the transcriptional and posttranslational activation of the transcription factor Prf1 (Pheromone-responsive factor 1). Prf1 is a central regulatory factor that controls mating and virulence [37-42]. Quantitative Real-time Polymerase Chain Reaction (qRTPCR) analysis showed that the addition of exogenous anthranilic acid inhibited the expression levels of pra, gpa3, uacl, adrl, prfl, $m f a, b E$ and $b W$, which encode the components of the PKA-cAMP pathway (Fig. 3c). Collectively, these results demonstrated that anthranilic acid inhibited expression levels of the components of PKAcAMP pathway to interfere with $S$. scitamineum sexual mating and filamentation (Fig. 3d).

\section{TrpEG is responsible for anthranilic acid biosynthesis in $R$. solanacearum}

In Pseudomonas aeruginosa, the enzymes encoded by $\operatorname{trpEG}$ and $p h n A B$ are the key enzymes involved in the biosynthesis of anthranilic acid [43]. There is an alternative biosynthesis pathway for anthranilic acid production in which the kynA, kynB, and kyn $U$ genes encode tryptophan 2,3-dioxygenase, kynurenine formamidase, and kynureninase, which decompose tryptophan to anthranilic acid [44]. To identify the genes responsible for anthranilic acid biosynthesis, trpEG homologues were first searched in the genome sequence of $R$. solanacearum GMI1000 and identified as RS_RS14430 and RS_RS14435 by using the National Center for Biotechnology Information Basic Local Alignment Search Tool (BLAST) program [45] (Fig. 4a). The deletion of RS_RS14430 and RS_RS14435 (trpEG) together almost completely abolished anthranilic acid production (Fig. 4b) but only resulted in a slight decrease in the growth rate of the bacterial cells in both rich and poor nutrient media (Supplementary Fig. 4). Interestingly, different from the trpE mutant of Pseudomonas aeruginosa, which did not grow in the minimal medium [46], the trpEG mutant of $R$. solanacearum GMI1000 grew well in MP minimal medium with a slight decrease of growth rate a
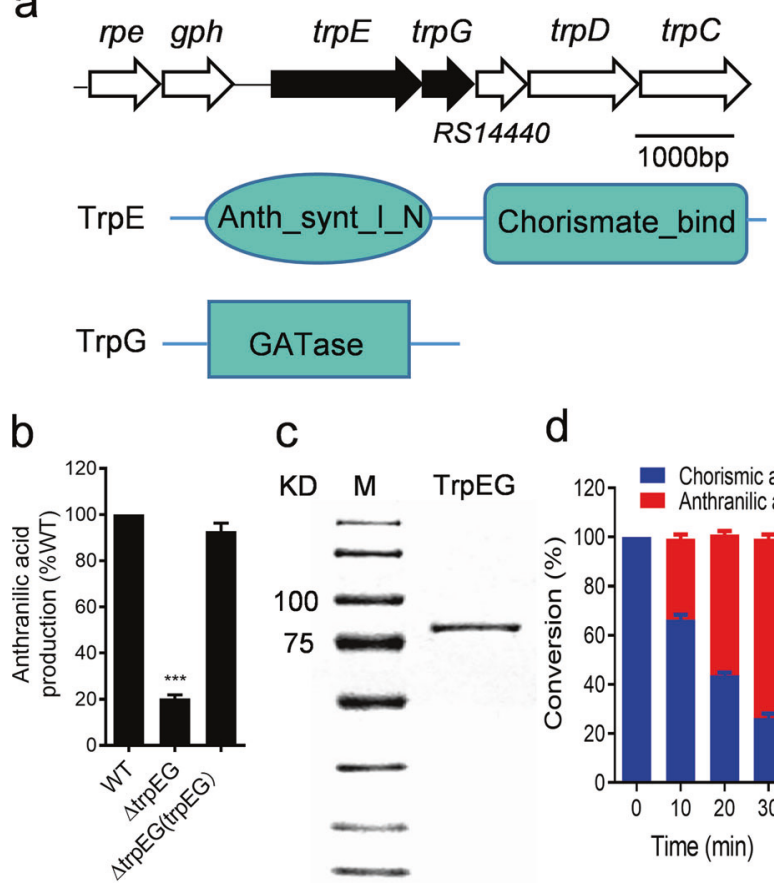

d

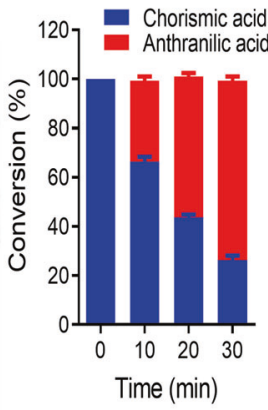

Fig. 4 Analysis of the enzyme activity of TrpEG in the synthesis of anthranilic acid. a Genomic organization of the $\operatorname{trpEG}$ region in $R$. solanacearum GMI1000 (top). Domain structure analysis of TrpE (middle) and TrpG (bottom). b Detection of anthranilic acid production via the LC-MS assay. c SDS-PAGE analysis of the TrpEG protein. d Analysis of the production of anthranilic acid by TrpEG to catalyse chorismic acid transformation. The data are means \pm standard deviations of three independent experiments. ${ }^{* * *} p<0.001$ (unpaired $t$ test).

compared with that of the wild-type strain (Supplementary Fig. 4). We also identified the homologues of $k y n A, k y n B$, and kynU in $R$. solanacearum GMI1000. The deletion of the three genes caused only a slight reduction of anthranilic acid production (Supplementary Fig. 5), but double deletion of the $\operatorname{trpEG}$ and $k y n A U B$ genes abolished anthranilic acid production completely (Supplementary Fig. 5). These findings indicated that TrpEG was the most important synthase for the biosynthesis of anthranilic acid in $R$. solanacearum.

To further confirm the observed enzymatic activity in vitro, the fusion protein TrpEG, which contains 698 amino acids and has a calculated molecular weight of 77.33 $\mathrm{kDa}$, was purified using affinity chromatography (Fig. 4c). In vitro enzyme activity analysis showed that TrpEG directly catalysed the transformation of chorismic acid to anthranilic acid (Fig. 4d; Supplementary Fig. 6).

\section{The production of anthranilic acid is cell density dependent}

To investigate whether the biosynthesis of anthranilic acid is related to cell density, we first measured the time course 
of anthranilic acid production by determining anthranilic acid concentrations at various growth stages. The amount of anthranilic acid was detectable and was first measured at $8 \mathrm{~h}$ postinoculation according to the standard curve of anthranilic acid (Fig. 5a; Supplementary Fig. 7). After this time point, anthranilic acid concentrations increased sharply during the exponential growth phase and peaked at $32 \mathrm{~h}$ in the late exponential growth phase, followed by a significant decline in the anthranilic acid concentration (Fig. 5a).

We continued to investigate the transcriptional profile of $\operatorname{trpEG}$, which controls anthranilic acid production. A 411bp DNA sequence containing the $\operatorname{trp} E G$ promoter region was transcriptionally fused to the lac $Z$ coding region and introduced into the wild-type and $\operatorname{trp} E G$ mutant strains. The transcriptional level of $\operatorname{trpEG}$ in the wild-type strain
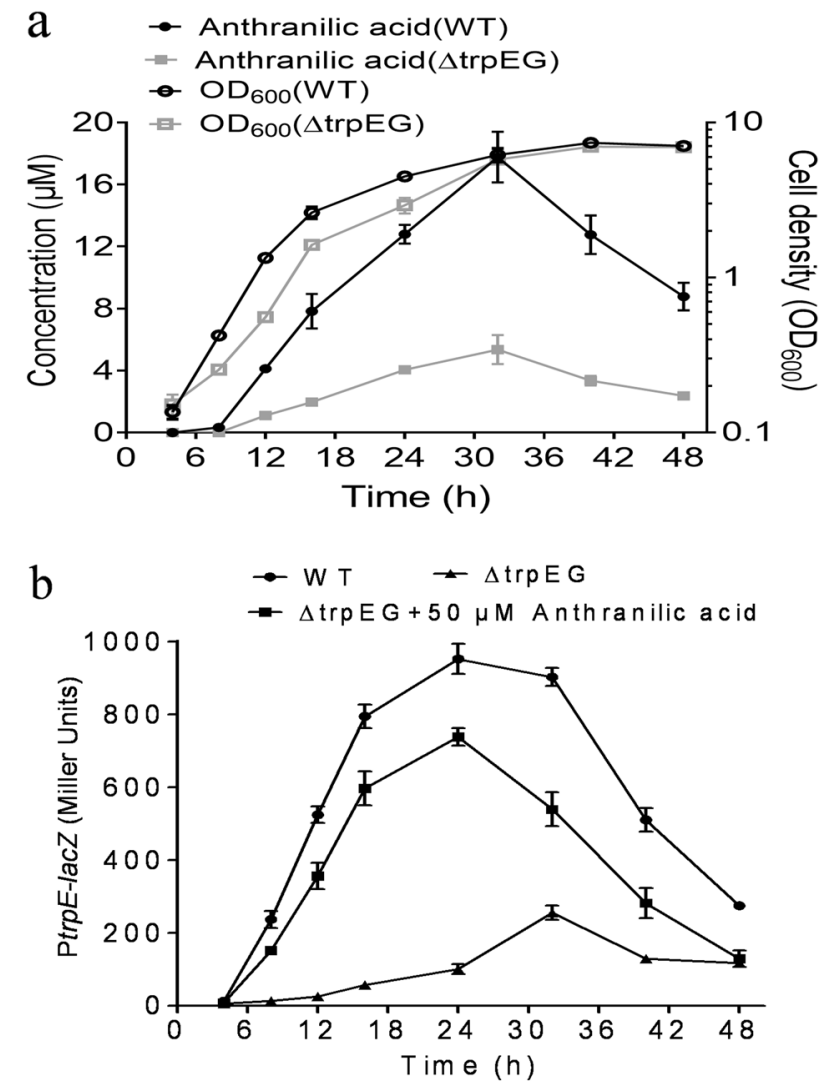

Fig. 5 Analysis of anthranilic acid production and trpEG transcriptional expression. a Time-course analysis of anthranilic acid accumulation in the $R$. solanacearum wild-type strain $(\mathbf{O})$ and the $\operatorname{trpEG}$ deletion mutant strain $(\square)$ and $R$. solanacearum cell growth in the wild-type strain (O) and the $\operatorname{trp} E G$ deletion mutant strain $(\square)$

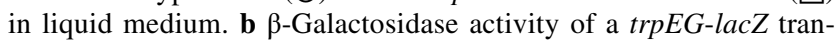
scriptional fusion in the $R$. solanacearum wild-type strain (O) and the $\operatorname{trpEG}$ deletion mutant strain $(\mathbf{\Delta})$ and the $\operatorname{trpEG}$ deletion mutant strain supplemented with anthranilic acid (ם). The $R$. solanacearum GMI1000 strains were inoculated in a $2 \mathrm{~L}$ flask containing $1 \mathrm{~L}$ TTC medium and cultured at $28^{\circ} \mathrm{C}$ with shaking at $220 \mathrm{rpm}$. The experiment was started at an initial $\mathrm{OD}_{600}$ of 0.05 . The data are means \pm standard deviations of three independent experiments. gradually increased and peaked at $24 \mathrm{~h}$ postinoculation, then decreased (Fig. 5b), which was well correlated with the anthranilic acid accumulation profile.

To test whether the transcriptional expression of $\operatorname{trp} E G$ is autoregulated by anthranilic acid, we compared the transcriptional profiles of $\operatorname{trp} E G$ in both the wild-type strain and the $\operatorname{trp} E G$ deletion mutant strain. The results showed that promoter activity in the mutant strain was decreased significantly from that in the wild-type background, and exogenous addition of anthranilic acid could almost restore the promoter activity in the $\operatorname{trp} E G$ deletion mutant strain to the levels in the wild-type strain, suggesting that the production of anthranilic acid may be autoregulated at the transcriptional level (Fig. 5b).

\section{Deletion of trpEG impairs biological functions in $\boldsymbol{R}$. solanacearum}

It was determined that anthranilic acid inhibits $S$. scitamineum sexual mating and morphological transition through inter-kingdom interference. We continued to study whether this compound plays a role in the regulation of biological functions in $R$. solanacearum. As the biosynthesis of anthranilic acid is mainly performed by TrpEG, we tested the phenotypes of biofilm formation, cellulase production, motility activity, and EPS production in an in-frame deletion mutant of $\operatorname{trp} E, \operatorname{trp} G$, and $\operatorname{trpEG}$. It was shown that the deletion of $\operatorname{trp} E G$ had little effect on the growth of bacterial cells (Supplementary Fig. 4) but resulted in significant impairment of these phenotypes (Fig. 6). Interestingly, both the in trans expression of $\operatorname{trpEG}$ and the addition of exogenous anthranilic acid restored these phenotypes of the $\operatorname{trpEG}$ deletion mutant to wild-type strain levels (Fig. 6). As expected, the two single deletion mutants, $\operatorname{trp} E$ and $\operatorname{trp} G$, showed the similar phenotypes as the trpEG double deletion mutant, and exogenous addition of anthranilic acid restored these phenotypes of the $\operatorname{trp} E$ deletion mutant and the $\operatorname{trp} G$ deletion mutant to the wild-type strain levels (Supplementary Figs. 8, 9). We also found that deletion of $\operatorname{trp} E$, $\operatorname{trp} G$ or $\operatorname{trpEG}$ abolished the inhibition on the sexual mating and hypha formation of $S$. scitamineum (Supplementary Fig. 10). Intriguingly, the deletion of kynAUB in both the wild-type and $\operatorname{trpEG}$ deletion mutant strains exhibited no effect on these phenotypes (Supplementary Fig. 11).

Quantitative Real-time PCR analysis showed that the mutation of $\operatorname{trpEG}$ caused a decrease in the expression levels of $p h c A, p h c B$, soll, epsA, epsB, epsC, epsD, epsE and epsF (Supplementary Fig. 12a). Among these genes, $p h c A$ and $p h c B$ encode the regulator and the signal synthase, respectively, while epsA-F are the target genes of the phc system. soII is the gene encoding the signal synthase of the sol system. Moreover, we also measured and compared the production of anthranilic acid, C8-AHL, C10-AHL and 
Fig. 6 Effect of $\operatorname{trpEG}$ and the anthranilic acid compound on the QS-regulated phenotypes of $R$. solanacearum. Motility (a), biofilm formation (b), EPS production (c) and cellulase production (d) in $R$.

solanacearum GMI1000 were analysed. The data are means \pm standard deviations of three independent experiments. ${ }^{*} p<$ $0.05 ; * * p<0.01 ; * * * p<0.001$ (unpaired $t$ test). a
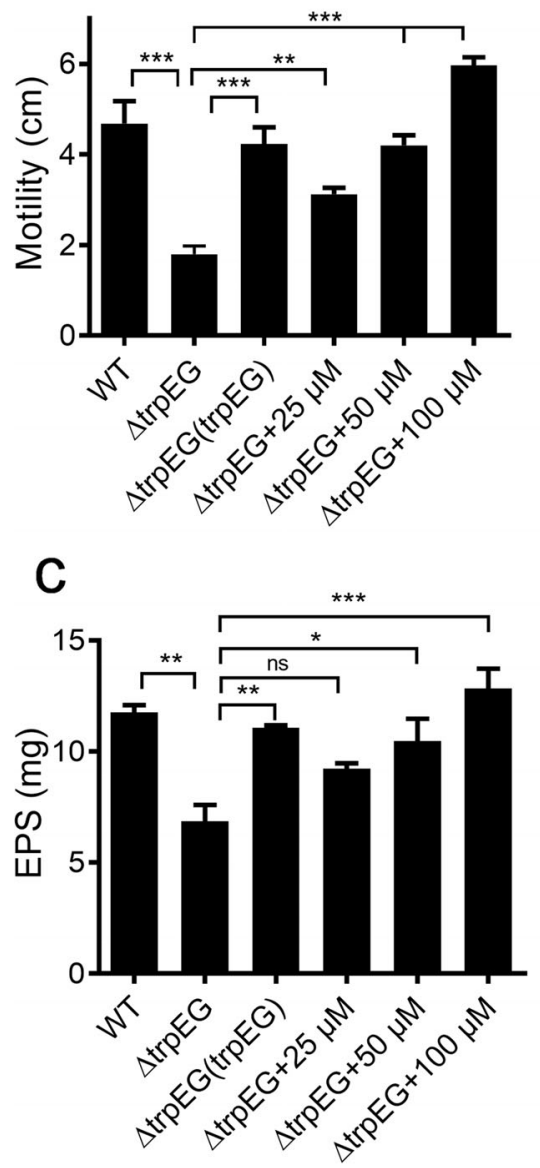

b

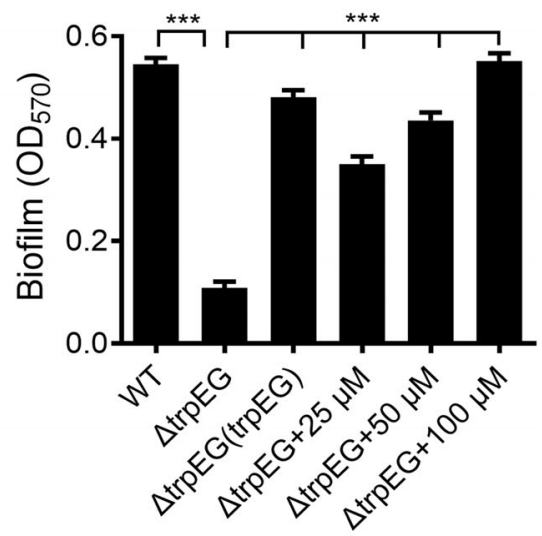

d

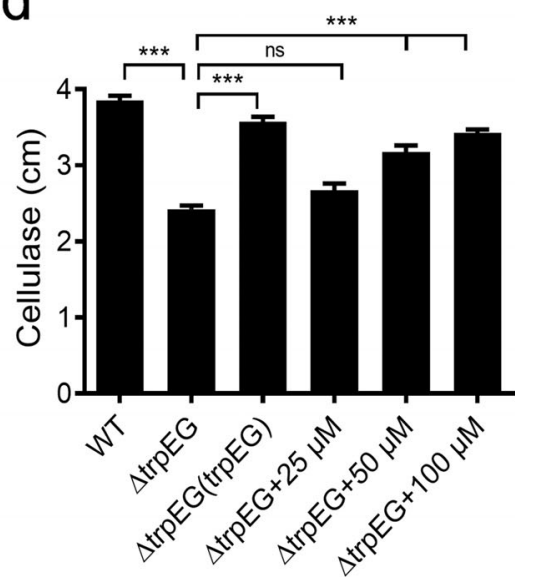

3OH-MAME in the trpEG mutant, $p h c B$ mutant and wildtype strains. We found that the production of anthranilic acid, C8-AHL, C10-AHL and 3OH-MAME was reduced in the trpEG mutant strain, while only the production of C8AHL, C10-AHL and 3OH-MAME was downregulated in the $p h c B$ mutant strain (Supplementary Fig. 12b). These results demonstrated that anthranilic acid/TrpEG positively regulated both the phc and sol QS systems in $R$. solanacearum.

\section{It is anthranilic acid rather than its metabolic products that controls the biological functions in $R$. solanacearum}

In Pseudomonas aeruginosa, anthranilic acid is a precursor for the biosynthesis of three QS molecules, 2,4dihydroxyquinoline (DHQ), HHQ and 2-heptyl-3hydroxy-4-quinolone (PQS) [47]. To finally determine whether anthranilic acid serves as a precursor for the signals or acts itself, we used liquid chromatograph mass spectrometer (LC-MS) analysis to check whether the ethyl acetate extract of the $R$. solanacearum supernatant contained PQS, HHQ, or DHQ on the basis of comparison with the standard signals. It was revealed that there was no PQS, HHQ or DHQ in the extract (Supplementary Figs. 13-15). In addition, the addition of exogenous PQS, HHQ, or DHQ caused no restoration of the phenotypes of the trpEG mutant strain (Supplementary Fig. 16), suggesting that it is anthranilic acid controlling the biological functions in $R$. solanacearum.

We then measured the gene expression levels of eps $A$ in the wild-type strain and the double deletion mutant strain $\Delta \operatorname{trpEG} \Delta \mathrm{kynAUB}$, which is anthranilic acid-deficient (Supplementary Fig. 5). As epsA was identified to be a target gene positively controlled by the anthranilic acid compound (Supplementary Fig. 12a), the result further confirmed that deletion of $\operatorname{trp} E G$ and $k y n A U B$ significantly decreased the promoter activity of epsA as expected (Supplementary Fig. 17). More interestingly, we found that exogenous addition of anthranilic acid at a final concentration of $1 \mu \mathrm{M}$ obviously increased the expression level of eps $A$ in the deletion mutant strain $\Delta \operatorname{trpEG} \Delta \mathrm{kynAUB}$; and addition of $20 \mu \mathrm{M}$ anthranilic acid fully restored the expression level of eps $A$ in the $\Delta \operatorname{trpEG} \Delta \mathrm{kynAUB}$ deletion mutant strain to the wild-type strain level (Supplementary Fig. 17), suggesting that there is a minimal threshold 
Fig. 7 Influence of $\operatorname{trpEG}$ on the virulence of $R$. solanacearum in tomato plants. a Analysis of $R$. solanacearum virulence in tomato plants. b Mortality of tomato plants after infection with the $R$. solanacearum wildtype, $\Delta$ trpEG and $\Delta \operatorname{trpEG}$ (trpEG) strains. CFUs of the $R$. solanacearum wild-type, $\Delta$ trpEG and $\Delta$ trpEG(trpEG) strains in the roots (c) and stems (d) of tomato plants. The data are means \pm standard deviations of three independent experiments. $* p<0.05 ; * * p<$ $0.01 ; * * * p<0.001$ (unpaired $t$ test). a
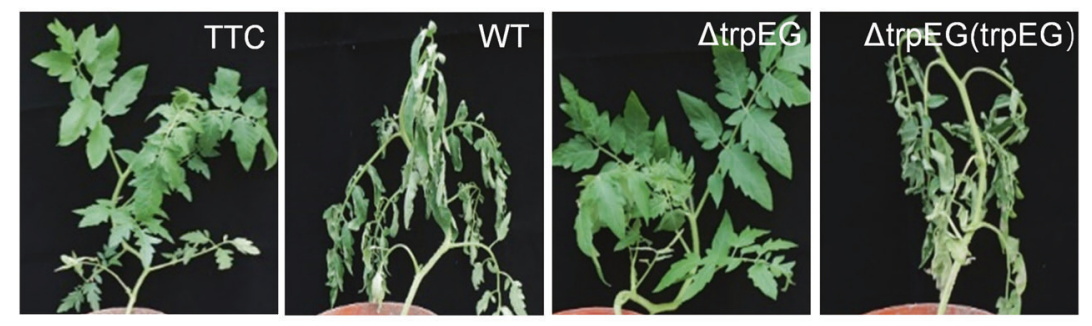

b
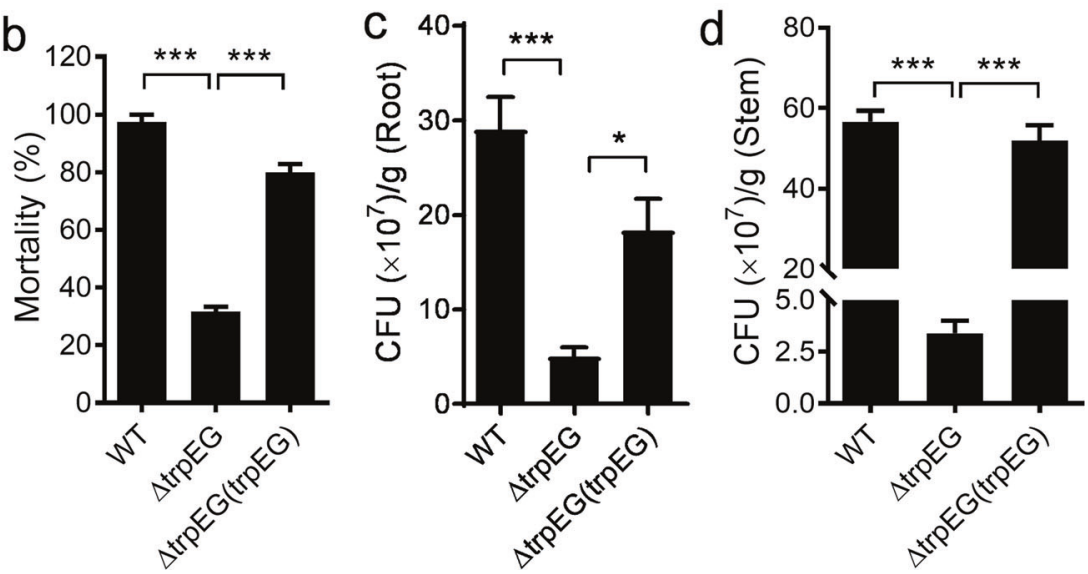

concentration of the anthranilic acid compound in regulating target gene expression in $R$. solanacearum.

\section{Anthranilic acid contributes to $R$. solanacearum pathogenicity}

To determine the role of anthranilic acid in $R$. solanacearum pathogenesis, the $R$. solanacearum GMI1000 wild-type strain, the $\operatorname{trp} E G$ mutant strain, and the complement strain were used to infect tomato plants. The plants treated with the $\operatorname{trpEG}$ mutant strain showed an obvious reduction of wilt symptoms compared with the plants infected by the wild-type and complement strains (Fig. 7a). Accordingly, the mortality of the plants treated with the $R$. solanacearum wild-type, $\operatorname{trpEG}$ mutant, and complement strains at $21 \mathrm{~d}$ was $97.5 \%, 31.7 \%$, and $80 \%$, respectively (Fig. $7 b$ ).

To further study the effect of anthranilic acid in the $R$. solanacearum infection process, we continued to quantify the colony-forming units (CFU) of $R$. solanacearum strains in both the roots and stems of the tomato plants. The CFUs recorded for the $R$. solanacearum wild-type, $\operatorname{trp} E G$ deletion mutant, and complement strains were $2.96 \times 10^{8}, 6.4 \times 10^{7}$, and $1.98 \times 10^{8}$ per gram of root tissue at $21 \mathrm{~d}$ postinoculation, respectively (Fig. 7c). A similar result was observed for tomato stems, in which the CFUs of the three strains were $5.67 \times 10^{8}, 3.4 \times 10^{7}$, and $5.2 \times 10^{8}$ per gram of stem tissue at $21 \mathrm{~d}$ postinoculation, respectively (Fig. 7d). These results suggest that anthranilic acid plays a vital role in the pathogenesis of $R$. solanacearum.

\section{Anthranilic acid controls the expression levels of a wide range of genes}

To determine the comprehensive regulatory roles of $\operatorname{trpEG}$ in controlling bacterial physiology, we analysed and compared the transcriptomes of the wild-type strain and the $\Delta$ trpEG mutant strain by using RNA Sequencing (RNASeq). Differential gene expression analysis showed that 227 genes were increased and 278 genes were decreased $\left(\log _{2}\right.$ fold-change $\geq 1.5$ ) in the $\Delta$ trpEG mutant strain compared with the wild-type GMI1000 strain (Fig. 8a and Supplementary Table 4 ). These differentially expressed genes were associated with a range of biological functions, including motility and cell attachment, stress tolerance, virulence, regulation, transcriptional regulators, membrane components, transports, multidrug resistance, detoxification and signal transduction (Fig. 8b and Supplementary Table 4). Quantitative RT-PCR analysis of select genes confirmed the RNA-seq results (Fig. 8c, d). These genes include the $p h c$ and sol systems and the eps gene cluster (epsA, epsB, epsC, $e p s D$, epsE and epsF). We also found that many flagellum genes, such as motA, $f l g K, f l g L, f l i Q, f l i P, f i D, f i i S, f i G$, $f i H$, and $f l i J$, were downregulated in the $\Delta$ trpEG mutant strain.

\section{Anthranilic acid is produced by many bacteria}

To investigate whether anthranilic acid is widely present in bacteria, $\operatorname{trpEG}$ homologues were searched in the genome 
Fig. 8 Differential gene expression profiles between the $R$. solanacearum GMI1000 $\operatorname{trpEG}$ mutant strain and the wild-type strain as measured by RNA-Seq $\left(\log _{2}\right.$ foldchange $\geq \mathbf{1 . 5}$ ). a A number of genes were upregulated and downregulated in $\triangle \operatorname{trpEG}$ compared with the wild-type strain. b GO term enrichment analysis of differentially expressed genes between the $\Delta$ trpEG and wild-type strains. Divergently regulated genes are not depicted in these diagrams but can be found in Supplementary Table 4. c, d qRT-PCR analysis of the genes that showed differential expression in the $\operatorname{trpEG}$ mutant strain compared with the wildtype strain.

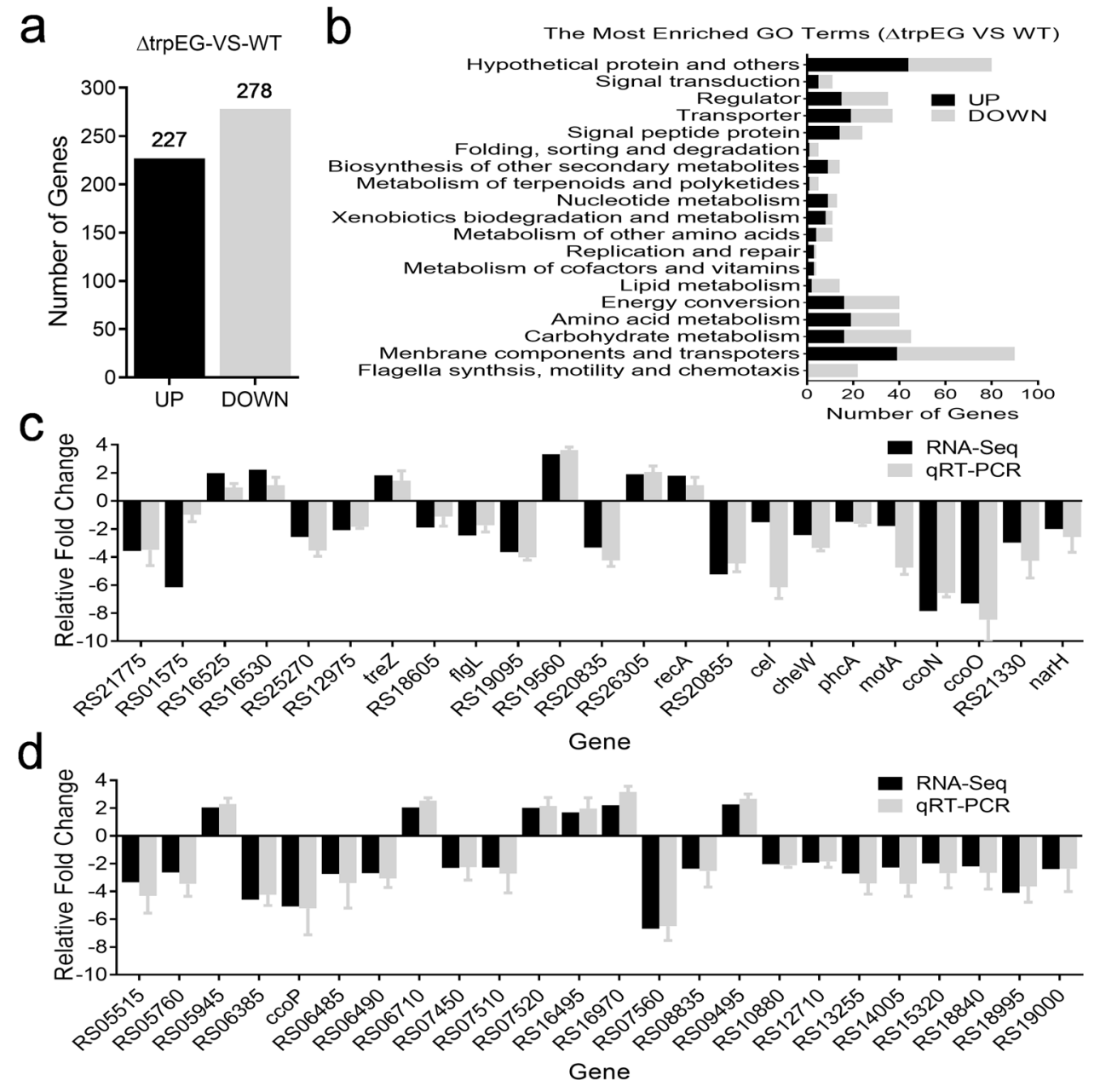

database by using the BLAST program. Many bacteria exhibited homologues of anthranilic acid synthase, which shared high similarity of their amino acid sequences (Supplementary Fig. 18 and Table 5). We then selected several bacterial strains and cultured them in liquid medium, then collected the supernatants after the cells had grown for $48 \mathrm{~h}$ $\left(\mathrm{OD}_{600}\right.$ of $\left.\sim 3.0\right)$. The ethyl acetate extracts of these strains were analysed by using LC-MS. The results showed that all the tested bacterial species (Burkholderia cenocepacia, Collimonas pratensis, $P$. aeruginosa, Achromobacter xylosoxidans, and Comamonas aquatic) produced high levels of anthranilic acid (Supplementary Fig. 19), indicating that the anthranilic acid compound might be widely conserved in bacteria.

\section{Discussion}

In soil and rhizosphere environments, $R$. solanacearum usually coexists with many other microorganisms. These bacteria and fungi compete for the same ecological niche and nutrient resources [23]. Therefore, the ability to cope with a range of competitors is essential for growth and survival in soil ecosystems. The results of this study identified a new weapon $R$. solanacearum GMI1000 against one of its competitors, the fungus $S$. scitamineum (Fig. 1). It was revealed that the $R$. solanacearum GMI1000 strain utilizes anthranilic acid to inhibit the sexual mating and morphological transition of $S$. scitamineum to achieve a competitive advantage (Figs. 1, 3). Some previous studies have also revealed that $R$. solanacearum employs QS to control the production of ralsolamycin to achieve a fitness advantage in inter-kingdom competition [24-26]. Our new findings suggested that complicated mechanisms have evolved in $R$. solanacearum to achieve for a competitive advantage in the microbial community.

In addition to its vital role in microbial ecology, anthranilic acid is very important for the bacterial physiology of $R$. solanacearum. It was indicated that the deletion of TrpEG caused a remarkable reduction in anthranilic acid production and serious impairment of the biological functions and pathogenicity of 
$R$. solanacearum, while in trans expression of trpEG or the addition of anthranilic acid restored these phenotypes in the $\operatorname{trpEG}$ deletion mutant strain (Figs. 4, 6, 7, 8). Increasing evidence has accumulated to support the multiple roles of QS signals or cues in both intraspecies signalling and interspecies interactions. Our previous studies have also indicated that in addition to their key roles in intraspecies signalling, DSF-family signals exhibit an important function in interspecies and inter-kingdom communication [48-51]. Our findings in this study establish the significant roles of the anthranilic acid compound in inter-kingdom communication as well as in intraspecies signalling regulation for the first time.

Both in vivo and in vitro experiments have demonstrated the enzymatic activity of TrpEG from $R$. solanacearum GMI1000 to synthesize anthranilic acid (Fig. 4). The comparison of peptide sequences revealed that TrpEG from R. solanacearum GMI1000 shares high identity (57.12\%) with the anthranilate synthase TrpEG from $P$. aeruginosa PAO1 [11, 12, 47]. In addition, we identified the homologues of kynA, kynB, and kyn $U$ in $R$. solanacearum GMI1000, which shared identities of $66.32 \%, 69.63 \%$ and $69.78 \%$ with their homologues in $P$. aeruginosa PAO1, respectively [44]. However, our findings from this study suggest that the anthranilic acid/TrpEG system can be distinguished from the relevant system in $P$. aeruginosa. This conclusion was supported by several lines of evidence. First, anthranilic acid is a precursor for the biosynthesis of DHQ, HHQ and PQS in P. aeruginosa, while these molecules were not found in $R$. solanacearum GMI1000 (Supplementary Fig. 13-15). Second, no homologues of pqs gene cluster, which are the synthases for DHQ, HHQ and $\mathrm{PQS}$, respectively, in $P$. aeruginosa were identified in $R$. solanacearum GMI1000. Finally, the addition of exogenous PQS, HHQ, or DHQ resulted in no restoration of the phenotypes of the $R$. solanacearum trpEG mutant strain (Supplementary Fig. 16). In general, our results demonstrate that anthranilic acid/TrpEG system in $R$. solanacearum has evolved independently and is distinguished from the pqs or other QS systems in P. aeruginosa.

BLAST searches revealed that the $\operatorname{trp} E G$ homologues are conserved in all other Ralstonia genomovars with high identities of more than $85 \%$. Furthermore, our findings indicate that both anthranilic acid and TrpEG are widely conserved in many other bacterial species, including $B$. cenocepacia, $C$. pratensis, $P$. aeruginosa, A. xylosoxidans, and $C$. aquatic (Supplementary Figs. 18, 19). In general, we have demonstrated that the anthranilic acid compound plays a vital role in the control of QS signal production, biological functions and virulence in $R$. solanacearum. Further investigation of this compound will expand our knowledge of the regulatory mechanism of pathogenicity in bacterial pathogens.
Acknowledgements This work was financially supported by the China National Natural Science Foundation (No. 31571969) and the Guangdong Natural Science Funds for Distinguished Young Scholars, China (No. 2014A030306015).

Author contributions YD and SS designed the research. SS, WY, XS, and BC performed the research. SS, WY, XS, BC, LH, PL, LY, JZ and YD analysed the data. SS and YD wrote the paper.

\section{Compliance with ethical standards}

Conflict of interest The authors declare that they have no conflict of interest.

Publisher's note Springer Nature remains neutral with regard to jurisdictional claims in published maps and institutional affiliations.

Open Access This article is licensed under a Creative Commons Attribution 4.0 International License, which permits use, sharing, adaptation, distribution and reproduction in any medium or format, as long as you give appropriate credit to the original author(s) and the source, provide a link to the Creative Commons license, and indicate if changes were made. The images or other third party material in this article are included in the article's Creative Commons license, unless indicated otherwise in a credit line to the material. If material is not included in the article's Creative Commons license and your intended use is not permitted by statutory regulation or exceeds the permitted use, you will need to obtain permission directly from the copyright holder. To view a copy of this license, visit http://creativecommons. org/licenses/by/4.0/.

\section{References}

1. Fuqua C, Greenberg EP. Signalling: listening in on bacteria: acylhomoserine lactone signalling. Nat Rev Mol Cell Biol. 2002;3:685-95.

2. Zhang LH, Dong YH. Quorum sensing and signal interference: diverse implications. Mol Microbiol. 2004;53:1563-71.

3. Deng Y, Wu J, Tao F, Zhang LH. Listening to a new language: DSF-based quorum sensing in Gram-negative bacteria. Chem Rev. 2011;111:160-73.

4. Fuqua C, Parsek MR, Greenberg EP. Regulation of gene expression by cell-to-cell communication: acyl-homoserine lactone quorum sensing. Annu Rev Genet. 2001;35:439-68.

5. Withers H, Swift S, Williams P. Quorum sensing as an integral component of gene regulatory networks in gram-negative bacteria. Curr Opin Microbiol. 2001;4:186-93.

6. Williams P. Quorum sensing, communication and cross-kingdom signalling in the bacterial world. Microbiology. 2007;153:3923-38.

7. He YW, Zhang LH. Quorum sensing and virulence regulation in Xanthomonas campestris. FEMS Microbiol Rev. 2008;32: 842-57.

8. Vendeville A, Winzer K, Heurlier K, Tang CM, Hardie KR. Making 'sense' of metabolism: autoinducer-2, LuxS and pathogenic bacteria. Nat Rev Microbiol. 2005;3:383-96.

9. Barrios AFG, Achenie LEK. Escherichia coli autoinducer-2 uptake network does not display hysteretic behavior but AI-2 synthesis rate controls transient bifurcation. Biosystems. 2010;99:17-26.

10. Flavier AB, Clough SJ, Schell MA, Denny TP. Identification of 3hydroxypalmitic acid methyl ester as a novel autoregulator controlling virulence in Ralstonia solanacearum. Mol Microbiol. 1997;26:251-9. 
11. Dulcey CE, Dekimpe V, Fauvelle DA, Milot S, Groleau MC, Doucet $\mathrm{N}$, et al. The end of a long-standing hypothesis: the Pseudomonas signalling molecules 4-hydroxy-2-alkylquinolines are derived from fatty acids, not 3-ketofatty acids. Chem Biol. 2013;20:1481-91.

12. Diggle SP, Matthijs S, Wright VJ, Fletcher MP, Chhabra SR, Lamont IL, et al. The Pseudomonas aeruginosa 4-quinolone signal molecules HHQ and PQS play multifunctional roles in quorum sensing and iron entrapment. Chem Biol. 2007;14:87-96.

13. Walters M, Sircili MP, Sperandio V. AI-3 synthesis is not dependent on luxS in Escherichia coli. J Bacteriol. 2006;188: 5668-81.

14. Loh J, Carlson RW, York WS, Stacey G. Bradyoxetin, a unique chemical signal involved in symbiotic gene regulation. Proc Natl Acad Sci USA. 2002;99:14446-51.

15. Tommonaro G, Abbamondi GR, Iodice C, Tait K, De RS. Diketopiperazines produced by the halophilic archaeon, Haloterrigena hispanica, activate AHL bioreporters. Micro Ecol. 2012;63: 490-5.

16. Genin S, Denny TP. Pathogenomics of the Ralstonia solanacearum species complex. Annu Rev Phytopathol. 2012;50:67-89.

17. Mansfield J, Genin S, Magori S, Citovsky V, Sriariyanum M, Ronald P, et al. Top 10 plant pathogenic bacteria in molecular plant pathology. Mol Plant Pathol. 2012;13:614-29.

18. Wicker E, Grassart L, Coransonbeaudu R, Mian D, Guilbaud C, Fegan M, et al. Ralstonia solanacearum strains from Martinique (French West Indies) exhibiting a new pathogenic potential. Appl Environ Micro. 2007;73:6790-801.

19. Kai K, Ohnishi H, Shimatani M, Ishikawa S, Mori Y, Kiba A, et al. Methyl 3-hydroxymyristate, a diffusible signal mediating phc quorum sensing in Ralstonia solanacearum. ChemBioChem. 2015;16:2309-18.

20. Clough SJ, Lee KE, Schell MA, Denny TP. A two-component system in Ralstonia (Pseudomonas) solanacearum modulates production of PhcA-regulated virulence factors in response to 3hydroxypalmitic acid methyl ester. J Bacteriol. 1997;179: 3639-48.

21. Garg RP, Yindeeyoungyeon W, Gilis A, Denny TP, Van DLD, Schell MA. Evidence that Ralstonia eutropha (Alcaligenes eutrophus) contains a functional homologue of the Ralstonia solanacearum Phe cell density sensing system. Mol Microbiol. 2010;38:359-67.

22. Mole BM, Baltrus DA, Dangl JL, Grant SR. Global virulence regulation networks in phytopathogenic bacteria. Trends Microbiol. 2007;15:363-71.

23. Tarkka MT, Sarniguet A, Frey-Klett P. Inter-kingdom encounters: recent advances in molecular bacterium-fungus interactions. Curr Genet. 2009;55:233-43.

24. Baldeweg F, Kage H, Schieferdecker S, Allen C, Hoffmeister D, Nett M. Structure of ralsolamycin, the interkingdom morphogen from the crop plant pathogen Ralstonia solanacearum. Org Lett. 2017;19:acs.orglett.7b02329.

25. Spraker JE, Sanchez LM, Lowe TM, Dorrestein PC, Keller NP. Ralstonia solanacearum lipopeptide induces chlamydospore development in fungi and facilitates bacterial entry into fungal tissues. ISME J. 2016;10:2317-30.

26. Li P, Yin W, Yan J, Chen Y, Fu S, Song S, et al. Modulation of inter-kingdom communication by PhcBSR quorum sensing system in Ralstonia solanacearum phylotype I strain GMI1000. Front Microbiol. 2017;8:1172.

27. Song S, Fu S, Sun X, Li P, Wu J, Dong T, et al. Identification of cyclic dipeptides from Escherichia coli as new antimicrobial agents against Ralstonia solanacearum. Molecules. 2018;23:214.

28. Yan M, Zhu G, Lin S, Xian X, Chang C, Xi P, et al. The matingtype locus b, of the sugarcane smut Sporisorium scitamineum, is essential for mating, filamentous growth and pathogenicity. Fungal Genet Biol. 2016;86:1-8.

29. Yan M, Cai E, Zhou J, Chang C, Xi P, Shen W, et al. A dual-color imaging system for sugarcane smut fungus Sporisorium scitamineum. Plant Dis. 2016;100:2357-62.

30. Cui C, Song S, Yang C, Sun X, Huang Y, Li K, et al. Disruption of quorum sensing and virulence in Burkholderia cenocepacia by a structural analogue of the cis-2-dodecenoic acid signal. Appl Environ Microbiol. 2019;85:e00105-19.

31. Cui C, Yang C, Song S, Fu S, Sun X, Deng Y. A novel twocomponent system modulates quorum sensing and pathogenicity in Burkholderia cenocepacia. Mol Microbiol. 2018;108:32-44.

32. Miltojevic A, Radulovic N. Complete assignment of ${ }^{1} \mathrm{H}-\mathrm{AND}$ ${ }^{13} \mathrm{C}$-NMR spectra of anthranilic acid and its hydroxy derivatives and salicylic acid and its amino derivatives. Facta universitatis Ser Phys Chem Technol. 2016;13:121-32.

33. Snetselaar KM, Mims CW. Sporidial fusion and infection of maize seedligs by the smut fungus Ustilago maydis. Mycologia. 1992;84:193-203.

34. Banuett F, Herskowitz I. Discrete developmental stages during teliospore formation in the corn smut fungus, Ustilago maydis. Development. 1996;122:2965.

35. Martínez-Espinoza AD, García-Pedrajas MD, Gold SE. The Ustilaginales as plant pests and model systems. Fungal Genet Biol. 2002;35:1-20.

36. Kahmann R, Kämper Jörg. Ustilago maydis: how its biology relates to pathogenic development. N. Phytol. 2004;164:31-42.

37. Hartmann HA, Kahmann R, Bölker M. The pheromone response factor coordinates filamentous growth and pathogenicity in Ustilago maydis. EMBO J. 1996;15:1632-41.

38. Hartmann HA, Krüger J, Lottspeich F, Kahmann R. Environmental signals controlling sexual development of the corn smut fungus Ustilago maydis through the transcriptional regulator Prf1. Plant Cell. 1999;11:1293-305.

39. Müller P, Aichinger C, Feldbrügge M, Kahmann R. The MAP kinase Kpp2 regulates mating and pathogenic development in Ustilago maydis. Mol Microbiol.1999;34:1007-17.

40. Müller P, Katzenberger JD, Loubradou G, Kahmann R. Guanyl nucleotide exchange factor Sq12 and Ras2 regulate filamentous growth in Ustilago maydis. Eukaryot Cell. 2003;2:609-17.

41. Brefort T, Müller P, Kahmann R. The high-mobility-group domain transcription factor Rop1 is a direct regulator of prf1 in Ustilago maydis. Eukaryot Cell. 2005;4:379-91.

42. Kaffarnik F, Müller P, Leibundgut M, Kahmann R, Feldbrügge M. PKA and MAPK phosphorylation of Prf1 allows promoter discrimination in Ustilago maydis. EMBO J. 2014;22:5817-26.

43. Déziel E, Lépine F, Milot S, He J, Mindrinos MN, Tompkins RG, et al. Analysis of Pseudomonas aeruginosa 4-hydroxy-2alkylquinolines (HAQs) reveals a role for 4-hydroxy-2heptylquinoline in cell-to-cell communication. Proc Natl Acad Sci USA. 2004;101:1339-44.

44. Farrow JM, Pesci EC. Two distinct pathways supply anthranilate as a precursor of the Pseudomonas quinolone signal. J Bacteriol. 2007; 189:3425-33.

45. Altschul SF, Gish W, Miller W, Myers EW, Lipman DJ. Basic local alignment search tool. J Mol Biol. 1990;215:403-10.

46. Palmer GC, Jorth PA, Whiteley M. The role of two Pseudomonas aeruginosa anthranilate synthases in tryptophan and quorum signal production. Microbiol. 2013;159:959-69.

47. Gruber JD, Chen W, Parnham S, Beauchesne K, Zhang YM. The role of 2,4-dihydroxyquinoline (DHQ) in Pseudomonas aeruginosa pathogenicity. PeerJ. 2016;4:e1495.

48. Boon C, Deng Y, Wang LH, He Y, Xu JL, Fan Y, et al. A novel DSF-like signal from Burkholderia cenocepacia interferes with Candida albicans morphological transition. ISME J. 2008;2:27-36. 
49. Deng Y, Boon C, Chen S, Lim A, Zhang LH. Cis-2-dodecenoic acid signal modulates virulence of Pseudomonas aeruginosa through interference with quorum sensing systems and T3SS. BMC Microbiol. 2013;13:231.

50. Deng Y, Lim A, Lee J, Chen S, An S, Dong YH, et al. Diffusible signal factor (DSF) quorum sensing signal and structurally related molecules enhance the antimicrobial efficacy of antibiotics against some bacterial pathogens. BMC Microbiol. 2014;14:51.

51. Deng Y, Wu J, Yin W, Li P, Zhou J, Chen S, et al. Diffusible signal factor family signals provide a fitness advantage to Xanthomonas campestris pv. campestris in interspecies competition. Environ Microbiol. 2016;18:1534-45. 